\title{
El Círculo de Obreros de Rosario ante el conflicto obrero y la crisis económico-social (1928-1935)
}

\author{
María Pía Martín
}

UNR - CIESAL - ISHIR - Conicet

mpiamartin_00@yahoo.com.ar

Title: The Rosario Workers' Circle in the face of labor conflict and socio-economic crisis (1928-1935)

Resumen: Nos proponemos estudiar las estrategias político-ideológicas y las prácticas del Círculo de Obreros de Rosario (COR) frente a los problemas sindicales y políticos que ofrecía el espacio municipal rosarino entre 1928 y 1935. Desde sus origenes el COR pretendia erigirse en referente de la clase obrera, dentro y fuera del campo católico. La prensa católica local llevó adelante el análisis de los conflictos iniciados hacia 1928 en Rosario y su zona circundante. Así el COR emprendió una campaña editorial destinada a trabajadores y ciudadanos católicos, en la que buscaba presentarse como una institución de orden identificada con la causa obrera.

Palabras clave: catolicismo social - política - conflicto - clase obrera

Abstract: The purpose of this article is to study the political-ideological strategies and practices of the Rosario Workers' Circle in the context of labor and political conflict within Rosario between 1928 and 1935. Since its inception, the Circle intended to establish itself as a model of the working class, both inside and outside of the Catholic sphere. The contemporary local Catholic press carried out an analysis of the disputes starting around 1928 in Rosario and its metropolitan area. In this way, the Circle began a media campaign directed at Catholic workers and citizens - the Circle meant to present itself as an institution of order that identified itself with the working class.

Keywords: Social Catholicism - politics - labor conflict - working class.

Recepción: 5 de abril de 2018. Aprobación: 1 de junio de 2018 .

(Archivos, año VII, $\mathrm{n}^{\circ}$ 13, septiembre de 2018, pp. 33-52) 
El Círculo de Obreros se radicó en Rosario en 1895, bajo la consigna de promover y defender los intereses de la clase trabajadora, oponiéndose a la influencia de las izquierdas y del liberalismo en todas sus formas. Desde su origen se presentó como una entidad católico-social que, no obstante su conocida actividad mutualista, pretendía erigirse en referente de legislación social y activismo en favor de los trabajadores, dentro y fuera del campo católico. Por tal motivo, fue definiendo posiciones frente a las huelgas. Si bien recurrió al envío de esquiroles en el puerto de Rosario en 1901 y 1902, no dejó de reconocer la posibilidad de la huelga parcial, cuando su causa pudiera considerarse justa, de indole estrictamente laboral y una vez agotadas todas las instancias de negociación. Por el contrario, rechazaba la huelga general, si bien un sector de demócratas cristianos participó de ellas en los conflictos portuarios de 1905. Los Círculos de Obreros (CO) no admitian el sindicalismo de carácter clasista, con sentido revolucionario o de resistencia, pero promovieron el sindicato profesional, reconocido por ley y sujeto al arbitraje estatal. En la década del 20, el COR era uno de los más importantes del país (Martín, 2012).

Hacia 1928 la ciudad de Rosario parecía convulsionada por cambios derivados de la política provincial, por coyunturas electorales y por una creciente tensión en el mundo del trabajo. Ante estos hechos, el COR se mostraba dispuesto a ensayar nuevas estrategias politicas y profundizar diversas acciones para promover el reformismo social en el municipio. Dos periódicos vinculados a él, La Verdad y El Heraldo, siguieron el desarrollo de los conflictos desatados en 1928, que afectaron la ciudad y su zona circundante. A partir de entonces sucedieron algunas huelgas de envergadura, como las de portuarios y tranviarios, el cese de actividad en la Refineria Argentina del Azúcar, sumado a la preocupación por los productores de la región. En este contexto el COR emprendió una campaña editorial, de propaganda y actividades concretas, mediante las cuales pretendia incidir en el espacio público, a la vez que procuraba mostrarse a sí mismo bajo un prisma que encerraba una paradoja: ser una institución de orden identificada con la causa obrera.

El propósito de este trabajo es estudiar las estrategias político-ideológicas y las prácticas del COR frente a los problemas sindicales y a las posibilidades políticas que ofrecía el municipio entre 1928, año electoral y de conflictos sociales para la ciudad, y 1935, marcado por la intervención de la Provincia de Santa Fe. Ese arco temporal supone un contexto atravesado por la crisis económica mundial, un creciente desempleo a nivel local y la presencia de las izquierdas tanto en el ámbito laboral, como en el de la política municipal.

Antes de introducirnos de lleno en el tema, creemos necesario analizar 
algunas ideas que circulaban entre sectores de la derecha de la época respecto de la democracia social.

Monseñor Gustavo J. Franceschi expresaba en su texto "Pan y democracia":

Si algo ha de hacernos experimentar el deber urgente de contribuir a transformar la democracia individualista que hoy padecemos en un régimen de mayor justicia, lo será sin duda alguna ese símbolo de los padecimientos sociales, el pan que llevamos a nuestra boca. (Franceschi, 1936)

Franceschi, director de la revista católica Criterio entre 1932 y 1957 , había participado desde joven de la democracia cristiana y sus organizaciones: Liga Democrática Cristiana, Liga Social Argentina, Círculos de Estudios Sociales e, incluso, Unión Popular Católica Argentina, antecedente de la Acción Católica (1931). No es extraño entonces que mostrara ese interés por la cuestión social. En el texto, un conflicto de panaderos servía de excusa para criticar a la democracia liberal y al capitalismo, reclamando cambios para lograr una sociedad y un régimen politico construidos sobre bases más justas. Sugería una mejor comprensión de los movimientos de masas que habian jalonado la historia desde la Revolución Francesa, indicando los límites de la "soberanía absoluta" del pueblo y de la idea de un "sufragio amorfo, igualitario y universal". La democracia liberal le parecia incapaz de articular las demandas y necesidades que requería la sociedad respecto de las políticas estatales. Al contrario, sus limitaciones revelaban los desajustes de un estado social en crisis, un orden carente de equilibrio y de justicia: "nos hallamos ante el dilema de reorganización o barbarie". Franceschi consideraba que la democracia individualista había abierto las puertas al capitalismo voraz de poderosos empresarios, de la banca internacional y de fuerzas económicas que avasallaban las naciones jugando "con vidas y haciendas" (Franceschi, 1936: 127).

Estas nociones se sostenían en la conocida crítica católica respecto del régimen liberal de gobierno, más un discurso anticapitalista presente también en los documentos papales (Pío XI, 1931). Si despejamos el componente moralizante de su discurso, su análisis dejaba translucir una idea de democracia fundada en el concepto de "bien común", una democracia más orgánica, sostenida sobre reformas que permitieran articular demandas y necesidades sociales, a fin de que el Estado pudiera garantizar la paz social.

La preocupación por la justicia social no era exclusiva de los católicos. En 1928, una conferencia de J.J. Díaz Arana en Rosario, auspiciada 
por el Partido Demócrata Progresista (PDP), se ocupaba de lo mismo. ${ }^{1}$ Si bien para Franceschi el problema era la democracia individualista concebida en sí misma, para Díaz Arana la democracia era "el estado normal de la sociedad". Sin embargo, en su perspectiva, una democracia auténtica no podía ser una simulación, ni su "corrupción demagógica", tal como se veía en la práctica (Díaz Arana, 1928: 7).

En ambos textos resulta dificultoso discernir a la democracia en sí -como abstracción- de las prácticas democráticas y su cotidianidad. Pero también ambos coinciden en la preocupación por el malestar de la masa de trabajadores: "si la democracia da hoy a esa mayoria el medio de operar la transformación social a que aspira, fluye la inutilidad de la acción violenta [sic]" (Díaz Arana, 1928: 15). Díaz Arana expresaba una fe irrevocable en la democracia individualista y liberal dentro de la cual, sin embargo, podría gestarse una correspondencia entre esfuerzo y retribución, volviendo innecesario el socialismo. Y presentaba la justicia social como clave para detener a la izquierda y avanzar hacia la pacificación de la sociedad.

Situado desde la defensa de la igualdad individual que supone la democracia, proponía una visión más flexible de las clases sociales, pasibles de movilidad ascendente, a pesar de la inevitable jerarquía que derivaba de la división del trabajo; y una acción política que permitiría, a través de la legislación, sancionar normas adecuadas para los problemas que afectaban a los trabajadores asalariados. La cuestión social remitía al bienestar y éste era más que el valor del salario, suponía elementos que lo excedían sobradamente. Para Díaz Arana, además de la ley, el movimiento cooperativo y el movimiento sindical eran herramientas de "emancipación y liberación económica". Por último, dado que en la democracia cabian todas las soluciones económicas, la opresión, la explotación y la inferioridad social de los obreros podía resolverse dentro de ella y no por fuera de la misma (Díaz Arana, 1928: 21-23).

Franceschi y Díaz Arana polemizaban con el marxismo, proponiendo una reforma legal y de funcionamiento del régimen político, pero uno lo planteaba por fuera de la democracia liberal y otro por dentro de ella.

Estos debates se dieron en Buenos Aires y Rosario en un contexto de crisis y de creciente insatisfacción social. La escalada de huelgas que se produjo en el sur de Santa Fe, con epicentro en Rosario, trascendió el plano local y encontró eco en la prensa nacional. Luego, el impacto de la crisis de 1929 en la Argentina mantuvo direccionadas estas preocupaciones que estaban ligadas a un nuevo estadio del capitalismo. Las

1. El folleto que hemos consultado no da referencias precisas, no obstante creemos que se trata de Juan José Díaz Arana, abogado dedicado a la economía política, quien presidió el Museo Social Argentino entre 1917 y 1918 (Zanzottera, 2015: 296-297). 
tensiones suscitadas a partir de esto ponían a la vista la posibilidad de "corregir" el sistema democrático vigente en un sentido más social. Nos centraremos en los años que preceden a la recuperación económica (1928-1935) a fin de abordar el momento más crítico de la cuestión social y politica en el orden local.

\section{Rosario y el problema obrero}

Desde mediados del siglo XIX Rosario vivió una rápida expansión gracias a la actividad de su puerto cerealista, que provocó un importante desarrollo comercial e industrial, además de constituirse en un punto clave de las lineas ferrocarrileras que recorrian la región. Todo ello dio lugar a la temprana presencia de una población obrera pluriétnica que fue desarrollando una experiencia sindical y politica acorde con el crecimiento de una ciudad que se convirtió en el centro articulador de la economía del sur santafesino. Precisamente, la Refinería Argentina del Azúcar, los Talleres del Ferrocarril Central Argentino y el Puerto delimitaban tres puntos de alta concentración de trabajadores, dando origen a barrios y zonas típicamente obreras. Muy pronto la ciudad albergó las corrientes de izquierda que caracterizaron al movimiento obrero argentino. En particular, los anarquistas constituyeron la fuerza sindical líder entre los portuarios y en la Refinería. Pero en los años 20, se habían fragmentado en antorchistas y foristas, a la vez que la presencia de socialistas, sindicalistas y comunistas era significativa. La conflictividad en el plano laboral parecía distendida por condiciones económicas relativamente favorables y por las estrategias patronales empleadas en la región (Menotti y Videla, 2013). Sin embargo, 1928 abrió una serie de conflictos de gran densidad que se prolongaron durante 1929. Aquel año, la coyuntura electoral dio el triunfo al radicalismo yrigoyenista $\mathrm{y}$, aunque las elecciones provinciales y municipales habian seguido el mismo sentido, una vez conquistado el poder, se produjeron otras fracturas dentro del partido gobernante. En los comicios municipales, por la aplicación de una nueva ley electoral, accedieron por primera vez al cuerpo deliberativo un concejal comunista y un socialista independiente.

La cuestión politica que aquí planteamos es clave para comprender todas las dimensiones del conflicto a nivel local, tanto como las estrategias y perspectivas de los católicos del COR al llegar 1928. Por un lado, las condiciones de vida y de trabajo de los obreros, la pobreza y el abandono de los barrios donde ellos se concentraban, eran motivo de reflexión y denuncia. Por otro lado, la conflictividad creciente en el campo sindical y las prácticas políticas del partido de gobierno dispararon una serie de acciones que evidenciaban el interés del COR por incidir en el espacio público mediante ideas, proyectos e iniciativas que 
neutralizaran a la izquierda y contribuyeran a la "paz social". A la vez, permiten explicar un giro de mayor dureza frente a la acción sindicalista en torno a mayo de 1928, momento en que cambiaron las autoridades políticas, según veremos más adelante.

Los periódicos La Verdad y El Heraldo fueron los principales portavoces del catolicismo social radicado en la ciudad. El primero de ellos era el órgano oficial del COR y había reaparecido en 1920 dando continuidad a experiencias anteriores. El segundo comenzó a publicarse en 1924, promovido por el obispo de Santa Fe y los demócratas cristianos vinculados al COR, tenía un perfil combativo e intransigente y se mantuvo hasta 1930 (Martín, 2014: 87-88). El enfoque de estos periódicos sobre los problemas del trabajo y la política local no estaba exento de una lectura crítica, de base moral y religiosa, ponia de manifiesto las tensiones de clase en las que todos estaban inmersos y permitía delinear un reformismo centrado en la "justicia social".

En 1927 el periódico La Verdad denunciaba la generalización del trabajo de menores en comercios, fábricas, talleres y casas particulares, debido a las necesidades de las familias pobres, a riesgo de perjudicar el desarrollo de sus hijos. Fustigaba en primer lugar a los empleadores que especulaban con la miseria del prójimo; y en segundo lugar, al Estado y sus funcionarios, que no hacian cumplir las leyes, permitiendo la explotación de los niños en sus lugares de trabajo. La Verdad sostenía que, dadas las condiciones sociales, no se podría suprimir el trabajo infantil, pero al menos debian disminuirse los riesgos y efectivizarse las leyes protectoras. ${ }^{2}$ Unos años después, el mismo periódico ataba la situación del niño y la mujer obrera a los males del liberalismo:

Nunca la sociedad, ni la familia se sintieron tan esclavos y humillados cuanto el liberalismo económico empujó a la mujer y al niño a la fábrica, obligados a trabajar en ellas para atender sus vidas y la de los suyos [...] Estos dos seres en el taller son un escarnio para la civilización, y un profundo agravio para la sociedad. ${ }^{3}$

La mujer no debía estar en el taller ni en la fábrica -"la mujer obrera es una lacra social"- porque su función era permanecer como "reina del hogar", atendiendo a su familia. ${ }^{4} \mathrm{Y}$ el niño, que era el futuro de la sociedad, debía formarse adecuadamente, preservar su salud e inteligencia, cultivarse en la escuela y en el ámbito familiar. Desde la

2. La Verdad, 10 de noviembre de 1927.

3. La Verdad, 15 de mayo de 1930.

4. La Verdad, 29 de septiembre de 1933. 
perspectiva católica, el trabajo los ponía en riesgo moral. Esos niños, jóvenes y mujeres trabajadores que tanto preocupaban a los católicos, un año después invadirian la ciudad en las violentas jornadas de huelga de los años 28 y 29. En piquetes, manifestaciones y enfrentamientos, conformarian un colectivo inédito y ciertamente numeroso que se hizo visible al calor de la contienda.

Los barrios obreros también atrajeron la mirada del COR desde una perspectiva dual. A la vez que reinvindicaba a la población pobre y trabajadora, apelaba al Estado para mejorar sus condiciones de vida, pues ello afectaba el desarrollo moral del pueblo trabajador. Si bien el periódico comenzaba por enaltecerlos:

Son los barrios obreros algo así como colmenares de las inteligentes y laboriosas abejas humanas, de esas abejas que elaboran el substancioso panal de la industria y del comercio. ¡Barrios obreros! Dichosas las naciones y las ciudades en las que abundan los colmenares del trabajo humano, nidos de forjadores de riqueza de todo género.

La existencia de esos barrios en una ciudad era indicio de laboriosidad, prosperidad y desarrollo, aditamentos que forjaban la imagen de urbe pujante que había construido la burguesía local sobre Rosario y que gozaba de un alto consenso dentro y fuera de ella. Pero, no obstante, había una percepción obscura sobre los populosos barrios obreros que distinguía La Verdad. Denunciaba desidia por parte de las autoridades locales: falta de vigilancia sobre su higiene, ausencia de educación, inexistencia de controles sobre la conducta, la economía y la previsión de sus habitantes. Y mencionaba al pasar que sólo se los atendía en coyunturas donde se requería el voto. ${ }^{5} \mathrm{El}$ descuido moral aludía a dos cuestiones, la vivienda y la presencia de cafés, boliches y despachos de bebidas. Respecto de la vivienda, la nota al pie de una foto publicada en 1931 clarifica la idea:

Este no parece el cuadro propio de una ciudad civilizada y culta. Sin embargo es aspecto de un conventillo del Barrio Refineria, sucio, intolerable, hacinador de conciencias y como antesala del delito. En él la promiscuidad de los sexos y de las personas estimula el desarrollo de los instintos. El conventillo es un ultraje a la dignidad humana, además de ser un buen combustible para la rebelión y el desenfreno de las clases 
trabajadoras. Nosotros queremos casas y no pocilgas para los obreros y sus familias. ${ }^{6}$

Rosario, ciudad culta y progresista, requería la reforma social. E1 hacinamiento, la falta de espacio y de higiene, generaban promiscuidad y embrutecimiento, y eran caldo de cultivo para el delito y el conflicto social. La vivienda higiénica, con espacios interiores bien diferenciados, aireada y saludable para la clase obrera, era una preocupación muy antigua entre estos católicos sociales. Los primeros proyectos pergeñados se ubican a fines del siglo XIX, aunque también inspiraron la Ley de Casas Baratas de 1915 y, a fines de la década del 30, llevaron a la Acción Católica y al COR a realizar una campaña a favor de la Ley de vivienda rural.

Una severa crítica se volcaba respecto de los lugares a los que concurrian los obreros jóvenes y adultos para beber luego del trabajo. En el primer caso porque se distraian de su cultivo personal -estudiar, perfeccionar su oficio- y generaba hábitos de derroche y de imprevisión; en el segundo caso, porque el tiempo dedicado al alcohol y al juego se quitaba a la familia, y afectaba la imagen frente a los menores y la sociedad. Este punto del artículo parecía dirigido a los trabajadores católicos, a los que interpelaba para que mostraran una conducta ejemplar, pensando en un cambio cultural de las clases menos favorecidas.

Finalmente, ya en el contexto de la crisis económica, el periódico acusaba la existencia de "caravanas de hombres desocupados" que abundaban cerca de las lineas férreas y en el norte de la ciudad. Eran extranjeros jóvenes, aptos para el trabajo, que pasaban hambre y vivían en la calle, ante la indiferencia de los poderes públicos y de las instituciones sociales. Revelaban la cara más dura del desempleo que afectó a la región. ${ }^{7}$

\section{Las huelgas de 1928-1929: acción obrera y política en la ciudad}

El 2 de mayo de 1928 se inició una huelga en el Puerto de Rosario, dado que las empresas exportadoras priorizaban trabajadores afines frente a los obreros sindicalizados. A esto se sumaban los pedidos salariales y de mejoras en las condiciones de trabajo. La huelga provocó primero la solidaridad de otros gremios y luego se articuló con nuevos conflictos en el corredor portuario del sur provincial y, más tarde, en el ámbito del proletariado rural. El movimiento adquirió grandes dimensiones, sobre todo a partir de la muerte de la obrera textil Luisa Lallana

6. La Verdad, 30 de enero de 1931.

7. La Verdad, 27 de febrero de 1930. 
a manos de un esquirol. La prensa de la época destacó la presencia de las compañeras, madres y hermanas de los obreros, que realizaron un manifiesto apoyando los reclamos de los hombres en paro. También repartieron propaganda a favor de los huelguistas entre los crumiros movilizados por la Liga Patriótica Argentina (LPA), quienes venían armados y llegaban desde Buenos Aires, Entre Ríos y otras localidades santafesinas. Uno de estos trabajadores, instigado por quien comandaba el grupo de rompehuelgas, asesinó a Luisa Lallana respondiendo al grito de "matalas, que yo respondo". Según el diario Democracia, la acción de la LPA en los conflictos había crecido amparada por el vicegobernador Juan Cepeda del radicalismo unificado (antipersonalista), ahora en retirada. ${ }^{8}$ La Iglesia católica local habia sostenido abiertamente el ascenso de este gobierno en 1924, a la vez que mantenía vínculos con la LPA y la Asociación del Trabajo, si bien estos no han sido debidamente estudiados.

A partir del asesinato de Lallana, que no fue el único, se desencadenaron dos huelgas generales con la activa participación en las calles de mujeres, jóvenes y niños. Hubo importantes niveles de confrontación entre trabajadores y rompehuelgas, que fueron los que provocaron las muertes y los heridos. Asimismo se distinguió por la ocupación de la calle, la protesta que acompañó la marcha fúnebre y los ataques a tranvias, destrozos en comercios, saqueos, pedradas y refriegas callejeras. ${ }^{9}$

La coyuntura política coincidió con el ascenso del radicalismo yrigoyenista en la provincia, mientras Ricardo Caballero era designado el 9 de mayo como jefe de Policía en Rosario. Este emblemático dirigente local era considerado por propios y ajenos como "obrerista", lo cual debió generar un clima favorable para la movilización. A decir de Mathew Karush "las fuerzas que habian sido utilizadas tradicionalmente para reprimir la protesta ahora estaban bajo el control directo de un defensor de los intereses de la clase obrera" (Karush, 2006: 72). El mismo 9 de mayo y el 21 se produjeron sendos paros generales declarados por los portuarios, el 27 pararon quienes trabajaban en fabricación de bolsas, el 26 los tranviarios, conflicto que se prolongó por casi dos meses; en junio y julio se sumaron la Refinería de azúcar, los fideeros de Minetti, conductores de carros y camiones. Finalmente, a la respuesta patronal centrada en notas a las autoridades, comunicados de prensa y reuniones interempresarias, se sumó el último mes un lock out. Así, el conflicto en

8. Democracia, 8 de mayo de 1928.

9. Esta huelga ha sido trabajada por Menotti y Videla (2013) y por Karush (2006). En el presente artículo nos hemos centrado en los aspectos del conflicto que son clave para abordar nuestro objeto. 
Rosario habria sido "una verdadera explosión proletaria que determinó el curso positivo de la huelga de estibadores" (Menotti y Videla, 2013: 3).

El Heraldo describía a comienzos de junio

[el] desborde de la canalla amparada por la policía, [que] hacía irrupción en nuestras calles, destruyendo impunemente cuanto encontraba a su paso [...] y detenía todas las actividades de la ciudad, sembrando pánico y dolor. ${ }^{10}$

En un plano abstracto, el periódico atribuía estos desmanes a la influencia de las ideologías modernas -tanto las izquierdas como el liberalismo- que habian hecho retroceder la idea de Dios y derribado los frenos que la moral religiosa imponía a los instintos de la masa; pero, en un plano más concreto, la mención de la policía sindicaba al propio gobierno de la ciudad como su causante. De este modo, las nuevas autoridades y sus funcionarios locales eran vistos como instigadores del conflicto social.

Un mes después, El Heraldo insistía sobre la sensación de angustia e incertidumbre que invadia la urbe. El cierre de comercios, el tráfico suspendido por los conflictos y un malestar permanente entre clases le hacia afirmar que "un hálito de tristeza reina por todas partes". ${ }^{11} \mathrm{Si}$ bien se reconocía el derecho a reclamar mejoras por parte de algunos gremios, también señalaba que estos debian sujetarse a los intereses generales. Mencionaba la injerencia de "elementos perturbadores", en alusión a los sectores de izquierda y -en igual magnitud- a la actitud asumida por las autoridades politicas de la ciudad. Reconocía la legitimidad de los reclamos, citando como ejemplo el caso de los tranviarios, cuyos bajos salarios la convertían en una causa "justa" y "razonable", y apelaba a la responsabilidad de los funcionarios y de los partidos -en particular el radicalismo- para resolver la situación. ${ }^{12}$ Reclamaba entonces la intervención de los poderes públicos y políticas adecuadas para resolver el conflicto. La ausencia de directivas claras se adjudicaba a la naturaleza de un gobierno nacido de "movimientos tornadizos de opinión, sin ideales ni programas definidos", destacando la pronta fractura de las autoridades que acababan de asumir.

El periódico tenía una lectura crítica sobre la política partidista y, más precisamente, sobre el radicalismo yrigoyenista. La situación comunal, por lo demás, estaba signada por la figura de Caballero. Este dirigente, al que se ha señalado como una expresión de populismo antes

10. El Heraldo, 2 de junio de 1928.

11. El Heraldo, 14 de julio de 1928.

12. El Heraldo, 14 de julio y 9 de agosto de 1928. 
del populismo, era el blanco de sus ataques, aún sin nombrarlo: "el pueblo sigue a sus mentores. Y sus mentores son hoy los que dirigen al electorado y a la muchedumbre..." Y agregaba que "el imperio de la demagogia" se extendía a la ciudad, a la provincia y a todo el país. ${ }^{13} \mathrm{El}$ endurecimiento del discurso del periódico obedecía en gran medida al cambio en la ecuación de gobierno que dominaba la política santafesina y su correlato local.

La problemática planteada por los católicos sociales tenía varias aristas. En primer término, la crítica al electoralismo y al oportunismo de los partidos que llegaban al poder; en segundo término, la necesidad de articular una legislación social adecuada, que se centrara en un arbitraje institucionalizado y en medidas que protegieran el trabajo obrero; y en tercer lugar, la intención de que los ciudadanos católicos asumieran esa doble identidad, apoyando candidatos propios que pudieran regenerar el sistema incorporando la reforma social.

1928 ofrecía una coyuntura apropiada para la acción partidista en el plano municipal. En las elecciones de ese año se aplicó por primera vez la nueva Ley orgánica municipal que incorporaba el cálculo de cargos por cociente, abriendo posibilidades a nuevas fuerzas políticas, lo cual favoreció el ascenso del Partido Comunista (PC) y el Partido Socialista Independiente (PSI) al Concejo Deliberante (Roldán, 2010: 169-180).

Debido al cambio de la situación política local y a las inéditas posibilidades de la izquierda a nivel comunal, más otras cuestiones que se arrastraban desde las elecciones provinciales de 1924, algunos sectores vinculados al COR venían organizando desde el año anterior un partido propio, la Unión Popular, que se presentó con sus candidatos a los comicios de noviembre. De esta experiencia nos interesa destacar el programa que ofrecía a la ciudad. El mismo proponía mejorar los servicios públicos como limpieza, iluminación, transporte y otros referidos a salud, asistencia pública y educación; acabar con el déficit municipal y nivelar gastos; crear mercados suburbanos para abaratar el consumo popular; represión del vicio y la inmoralidad; estabilidad y escalafón, descanso semanal, salario mínimo, jornada limitada para el trabajador municipal y en las empresas vinculadas a la comuna; facilitar su acceso a la vivienda y fomentar el cooperativismo, entre otras cosas. ${ }^{14}$ Sin embargo, el resultado obtenido no fue el esperado. Habian accedido candidatos que consideraban "enemigos" del catolicismo, mientras la derrota de la Unión Popular había sido total. La misma se adjudicaba a los tibios ciudadanos católicos que habrian temido perder

13. Ibidem.

14. El Heraldo, 10 y 17 de noviembre de 1928. 
el voto eligiendo candidatos de un partido clerical recién fundado. ${ }^{15} \mathrm{En}$ realidad, si bien el catolicismo pudo organizar un partido con un programa de orientación social, la Iglesia o sus hombres parecían incapaces de sustituir anteriores lealtades políticas, que contaban con sustento popular, como las distintas tendencias del radicalismo o la democracia progresista, o de detener el progreso de las fuerzas de izquierda que intervenían en el plano municipal. A la hora de votar, el católico común parecia preferir a dirigentes insertos en los partidos tradicionales, con arraigo en la región o en la ciudad, antes que un partido de sospechoso tinte confesional.

Hacia diciembre de 1928 la mirada de El Heraldo se endurecía e identificaba los disturbios de origen obrero al "régimen de los soviets". A su juicio, si bien Rosario pasaba por una tregua, la calma estaba lejos de haberse logrado, pues el conflicto se había desplazado a las zonas agrícolas de Santa Fe y Córdoba. Discursivamente se contraponía una población rural "laboriosa y pacífica" a la enervación de los dirigentes de izquierda, "jefes de la gavilla bolchevique", "verdaderas bandas de facinerosos [que], arma en ristre, amenazan con la destrucción de sementeras y los parvales y atentan contra la vida de los agricultores". ${ }^{16}$

La situación provincial se complicó ante la intervención militar de ese mes, mientras en abril del año siguiente una nueva intervención afectó al poder legislativo y judicial, poniendo en cuestión la autonomía provincial. El primer caso se justificaba por el conflicto agrario; el segundo, por un partidismo faccioso y una legislatura provincial inoperante que habria devenido en "comité político". ${ }^{17}$

En los conflictos de 1929 se acentuaron cuestiones que tenían que ver con la actividad comunista en la región, a cuyos miembros se los consideraba agitadores profesionales, incluso al concejal que representaba al PC. El periódico los acusaba por el empleo de armas para imponer los pliegos en favor de los braceros. Este análisis ponía el "peligro comunista" en primer lugar, visto como una amenaza para el conjunto de la sociedad, en un contexto donde el PC aparecía como una fuerza dinámica y altamente combativa (Camarero, 2007).

Por otro lado, hacia agosto de 1929, la percepción de El Heraldo sobre los conflictos obrero-patronales habia cambiado. Rosario, una ciudad populosa y económicamente promisoria, comenzaba a ser presentada como una urbe turbulenta. Las fuerzas izquierdistas de orientación revolucionaria, el activismo y la incipiente presencia comunal del PC parecian alumbrar los peores presagios. La conflictividad de la ciudad

\section{Ibidem.}

16. El Heraldo, 11 de diciembre de 1928.

17. El Heraldo, 8 de diciembre de 1928 y 27 de abril de 1929. 
irradiaba la campaña, cambiando su perfil pacífico y bucólico, por otro que barruntaba la insurrección. Se pasó entonces a descalificar los motivos del conflicto: no había una causa económica real, era un artificio creado por el "comunismo rojo" ante la pasividad de autoridades "pusilánimes" incapaces de detener esa avanzada. Y se agregaba a los judíos, dueños de las grandes riquezas del país, como cómplices de los agitadores de izquierda, pues ambos no harian más que oprimir a las masas proletarias avivando el malestar social. ${ }^{18}$

No obstante el panorama agorero reflejado por la prensa católica local, una nota enviada por el COR a la Cámara de Diputados de la Nación en 1929 señalaba algunos motivos del conflicto regional, a saber, las legítimas aspiraciones de mejora por parte de los obreros; la afirmación del derecho de asociación; la solidaridad de clases; las maniobras de especulación de sectores vinculados al comercio de productos del agro; la influencia de elementos extraños a los trabajadores y la gimnasia revolucionaria. Mientras los tres primeros puntos parecian medirse positivamente, los últimos resultaban absolutamente impugnables. Nuevamente se legitimaban los intereses obreros desde un lugar de orden, a tono con la paz social.

El COR proponía como solución la sindicalización obligatoria establecida por ley, a fin de neutralizar las tendencias que ponian en riesgo los valores de "Dios, Patria y Familia", aunque, de forma inédita, interpretaba la libertad de trabajo como un recurso de los capitalistas para mantener situaciones míseras de explotación e insistía en el desarrollo de una legislación más justa y previsora. ${ }^{19}$ El Heraldo y La Verdad insistían en la necesidad de una organización sindical sostenida por el Estado, que permitiera neutralizar caudillismos e ideas revolucionarias. Asimismo sugerian la creación de tribunales de arbitraje para la resolución de conflictos. No obstante, el contexto de conflictividad planteaba una visión rígida del tema. Así, en 1930 La Verdad también propiciaba una ley de Asociaciones profesionales que contemplara la disolución de sindicatos con fines revolucionarios y una legislación más estricta sobre huelgas. Al mismo tiempo, reaparecía la antigua noción de "defensa social", entendida como un "imperativo categórico que entra en el cuadro de las obligaciones del poder público", a modo preventivo, para garantizar la vida y la paz ciudadanas. ${ }^{20}$

18. El Heraldo, 3 de agosto de 1929; La Verdad, 8 de agosto de 1929.

19. La Verdad, 12 de septiembre de 1929; El Heraldo, 4 de enero de 1930.

20. El Heraldo, 4 de enero y 22 de marzo de 1930; La Verdad, 28 de diciembre de 1930. 


\section{La crisis y la desocupación}

A fines de la década del 20, debates vigentes en la Europa de entreguerras se difundieron en la Argentina y también en Rosario. Los periódicos católicos que venimos trabajando reprodujeron controversias en torno a las dictaduras modernas, la validez del sistema democrático, la cuestión de su representatividad y su posible sustitución por un régimen corporativo similar al de la Italia fascista (Martín, 1993).

Al promediar el año 29, El Heraldo asociaba al gobierno radical -y con él al sistema democrático- con la crisis de valores y la inseguridad social, mostrando una disposición favorable a formas de gobierno autoritarias que restablecerian el orden, creando bases firmes frente a un futuro dominado por la incertidumbre. Una vez consumado el golpe de 1930 y luego de cierta ambigüedad inicial, el COR pudo establecer conexiones que resultaron fructíferas, recibiendo algunos de sus hombres designaciones de relativa importancia. Entre ellas merecen destacarse, por su carácter estratégico frente al problema obrero, las designaciones de Francisco Casiello ${ }^{21}$ como Inspector Jefe del Departamento Provincial del Trabajo en 1930 y de Guillermo Ruiz Díaz ${ }^{22}$ como delegado de la Inspección Nacional del Puerto de Rosario en 1931 (Martín, 2012: 396-399).

A partir del golpe de Estado en 1930 y ante el impacto de la crisis mundial, el COR comenzó a interpelar al gobierno provisional, en un contexto en el que las políticas gubernamentales respecto de ciertos sectores políticos y sociales se volvían más rígidas, a la vez que se esperaban medidas restrictivas para sortear las dificultades económicas. En octubre de ese año, La Verdad difundía un comunicado de la Junta de Gobierno de los CO contra ciertos reclamos empresariales, como la suspensión temporal del descanso dominical, de la jornada de ocho horas y la aplicación de la ley que ampliaba funciones del Departamento Nacional del Trabajo. La Junta afirmaba que defendería "con toda energía" las pocas leyes obreras existentes y remarcaba el involucramiento que los $\mathrm{CO}$ habian tenido con ellas desde sus origenes. ${ }^{23} \mathrm{~A}$ partir de entonces fueron recurrentes sus pronunciamientos sobre las leyes de trabajo, la preocupación por el desempleo creciente y la propuesta de variadas iniciativas al respecto.

21. Dirigente del COR y de la democracia cristiana local, estuvo vinculado al antipersonalismo, llegó a ser senador provincial en 1939 y diputado nacional en 1942. Él y sus hermanos fueron muy cercanos a los obispos Juan A. Boneo y Antonio Caggiano.

22. Guillermo Ruiz Díaz, también militante demócrata cristiano desde su juventud, llegó a estar en la Comisión Directiva del COR y fue director del periódico La Verdad previo a su designación como funcionario.

23. La Verdad, 15 de octubre de 1930. 
El COR postulaba la necesidad de una mayor presencia del Estado para atender las necesidades de los "débiles e indigentes", constituyéndose en "providencia de los trabajadores" más vulnerables. Debía intervenir para evitar la "opresión del débil por el fuerte", entendiendo que en la disputa entre el capital y el trabajo, el obrero era la parte más débil y requería del poder estatal. ${ }^{24}$

El problema del desempleo fue abordado de varias maneras durante los años siguientes: por un lado, solicitando al gobierno nacional, provincial o al municipio la realización de obras públicas; en segundo lugar, procurando comprometer a esos poderes en el cumplimiento incondicional de las leyes existentes y promoviendo otras nuevas; y en tercer lugar, interviniendo en casos puntuales para evitar cierres, despidos o malas condiciones de trabajo.

La realización de obras públicas era vista como una solución que sólo podía dar el gobierno, utilizando recursos que se compensarian por el mejoramiento de la ciudad; moralmente, devolvian su dignidad al trabajador desempleado; y por último, evitarian el conflicto social y por tanto su secuela más temida, el avance de la izquierda.

Durante el año 1932, que marcó cifras elevadas de desempleo, coinciden demandas al gobierno nacional y provincial mediante diversas notas enviadas por los dirigentes del COR. En la provincia, el periódico denunciaba que a las familias trabajadoras las acuciaba el hambre y que, ante el riesgo de cesanteo, se cometían abusos que eran ignorados por el Departamento Provincial del Trabajo. Tanto las empresas extranjeras, como las concesionarias del Estado incurrian en ello, sobre todo contra los inmigrantes. ${ }^{25}$ Señalaba que la misión del DPT era "esencialmente social y apolítica", censurando tanto la complicidad como la demagogia, y entendía que sólo debía abocarse a controlar el cumplimiento de las leyes. ${ }^{26}$ Respecto del Concejo Deliberante, que había autorizado a invertir 20.000 pesos en obras públicas, el COR solicitaba que se multiplicara diez veces esa cifra, ya que era "irrisoria para la capacidad económica y contributiva de la Ciudad". ${ }^{27}$

La Verdad mostraba una actitud más crítica frente al gobierno de Ricardo Molinas (PDP) que administró la provincia entre 1932 y 1935. Éste se propuso restablecer la Constitución de 1921, que incorporaba cambios preocupantes para la Iglesia local. Incluso en los temas sociales y de trabajo, los católicos lo veían como un gobierno adverso. Por el contrario, primaba una mirada positiva sobre la autoridad nacional, si

24. La Verdad, 28 de noviembre de 1931 y 5 de junio de 1932.

25. La Verdad, 15 de junio de 1932.

26. La Verdad, 15 de abril de 1932.

27. Ibidem. 
bien por el momento las expectativas no se veían particularmente satisfechas. Finalmente, la gestión de Molinas terminó con una intervención que abriría paso a las fuerzas conservadoras representadas por José Maria de Iriondo a partir de 1937, hombre cercano a la Iglesia y proclive a favorecer el crecimiento de sus instituciones laicales.

Existía una aparente dualidad entre interpelar y a la vez avalar a los gobiernos conservadores en el orden nacional. Esto en el plano local se expresaba en una intervención explícita respecto de las cuestiones obreras que se planteaban. Estos católicos sociales, en realidad, pretendian colocarse como interlocutores privilegiados ante la autoridad pública nacional, frente a un gobierno que les resultaba más afin (Martín, 1997: 59-79). Pretendian erigirse al mismo tiempo en defensa de los intereses de la clase trabajadora y del orden social ocupando un lugar que, en el primer aspecto, era el espacio de los sindicatos y las agrupaciones de izquierda; y en el segundo aspecto, pretendía desplazar a gremios y dirigentes vetados por su ideología. Aunque en parte el crecimiento del COR en la década del 20 revelaba vínculos efectivos con el mundo del trabajo, también era cierto que un guiño positivo de las autoridades le hubiera permitido tener una mayor visibilidad y, por tanto, avanzar en su proyecto sobre las clases populares.

El temor al conflicto social permanecía indemne frente a las necesidades de los asalariados pobres y desocupados: "el hambre está llamando con insistencia a los hogares proletarios y el hambre es mala consejera y predispone a los mayores excesos" y acusaba a los "extremistas, las burguesías liberales y el capitalismo judío", tanto como a los gobiernos, que "juegan a la demagogia, sin percatarse de que están jugando con fuego". En una clara alusión al gobierno de Molinas, sostenían que la bandera de la "guerra religiosa" destruiría la espiritualidad de las masas, perjudicando a la sociedad en su conjunto y poniendo en riesgo la paz. ${ }^{28}$

El COR mostraba preocupación por las ollas populares que se realizaban en la ciudad y por aspectos culturales, como la banalización del desempleo por parte de las clases acomodadas; además pedía frenar el cierre de empresas y mejorar las condiciones de trabajo, incorporando leyes destinadas al bienestar de la familia obrera. Reveló también un particular interés respecto de descuentos aplicados a trabajadores del Estado para paliar la crisis y por el cierre de la Refinería Argentina del Azúcar en $1933 .{ }^{29}$ Esta Refinería, instalada a fines del siglo XIX en Rosario, había dado lugar a la formación de un importante barrio obrero.

28. La Verdad, 15 de junio de 1932.

29. La Verdad, 27 de junio de 1931, 10 y 26 de octubre de 1932 y 15 de septiembre de 1933. 
Su cierre significaba el desempleo de un número significativo de trabajadores y ponía en cuestión la propia identidad barrial. Decía La Verdad:

La clausura de esta fábrica, que tiene paralizado varios miles de brazos que no encuentran otra ocupación en época tan difícil, ha sembrado la miseria en toda la zona industrial del Municipio, con los consiguientes cuadros de angustia proletaria. ${ }^{30}$

El COR envió sucesivas notas a los Ministros de Hacienda y Agricultura de la Nación, al Presidente de la Cámara de Diputados de la Nación y al Presidente de la Comisión Nacional del Azúcar, analizando el impacto que esto tendría en la economía rosarina. ${ }^{31}$ La nueva estrategia empresarial para el refinamiento y la comercialización del azúcar dejaba fuera a Rosario, concentrando toda la actividad junto a los centros de producción al norte del país. La negativa a revertir esa decisión y la no intervención de la Comisión Nacional del Azúcar fueron interpretados como evidencia de una "mentalidad capitalista" preocupada por sus ganancias y ajena a cualquier criterio de justicia y caridad. El COR también hacía referencia a sus vínculos con la Agrupación de Ex Empleados de la Refinería, dando cuenta de que algunos de sus socios pertenecian a esa entidad y que recibian un apoyo de la institución que excedía la mera acción mediadora, brindando probablemente asistencia jurídica o material, "hasta tanto sea un hecho la reapertura de la Refinería Argentina". ${ }^{32}$

Otra cuestión de interés para el COR fue la construcción de comedores y baños en el Puerto destinados a los obreros de carga y descarga de productos. Al respecto, describía una situación "degradante", de "indiscutible gravedad" y carente de higiene aunque, sin embargo, la solución era sencilla. Continuando con su práctica, la conducción del COR envió entre 1930 y 1933 diversas notas a las autoridades nacionales reclamando que se hicieran obras semejantes a las que existian en Buenos Aires con ese fin. Los argumentos buscaban articular diversas facetas del problema: la medida implicaba un trato más justo y digno hacia el trabajador portuario, se correspondía con la envergadura de un Puerto ubicado entre los primeros del país, pero que además permitiría suprimir un "motivo de rebeldia proletaria, foco propicio de doctrinas más exóticas...", y favorecería a su vez la imagen del gobierno provisional. La iniciativa del COR incluia un proyecto de construcción, su

30. La Verdad, 15 de septiembre de 1933.

31. La Verdad, 25 de mayo y 15 y 29 de septiembre de 1933.

32. Ibidem. 
presupuesto y el modo de financiamiento, el cual fue aprobado por el Presidente Justo luego de tres años, aunque con modificaciones. ${ }^{33} \mathrm{Si}$ bien el COR obtenía algunas respuestas del gobierno nacional a sus demandas, éstas no se caracterizaban por la celeridad en su ejecución.

Por último, en legislación, además de la defensa de la jornada de 8 horas y del descanso dominical, propiciaban el salario familiar, el mutualismo y la autonomía de las bolsas de trabajo sostenidas por entidades particulares -el COR era una de ellas- e, incluso, la participación del trabajador en las ganancias. Estas reformas destinadas a la familia obrera darian como resultado hijos "útiles a la sociedad y la patria" y capaces de progresar, alcanzando el ascenso social. ${ }^{34}$

Las tácticas que venimos describiendo, utilizadas a modo de presión, interpelando o pretendiendo colaborar, expresadas en notas a autoridades, petitorios, proyectos o preproyectos, se repitieron durante la década y media que siguió, en la antesala del Peronismo (Lida, 2015: 174-176).

\section{Conclusión}

Hasta aquí hemos analizado los años de tránsito a la década del 30 abordando, por un lado, la formulación temprana de una idea de democracia social por parte de los católicos que ponía en cuestión la versión liberal y el abuso capitalista atribuidos a la democracia vigente; por otro lado, enfocamos la ciudad de Rosario con el objeto de comprender mediante qué estrategias los católicos locales procuraron hacer frente a la conflictividad política y social, en el marco de una concepción de justicia y bienestar que pretendia restaurar el orden.

En el discurso de la prensa católica consultada, se presentaba con claridad la necesidad de transformar cada vez más el Estado y volverlo garante de la justicia social, lo cual haría posible detener el avance de la izquierda y depuraría el sistema político de un partidismo vacuo.

Entre 1928 y 1930, una efectiva condensación del conflicto obrero en Rosario y su región estuvo asociada, en la perspectiva de distintos sectores de la derecha y en particular de los católicos sociales, con el triunfo de los radicales yrigoyenistas, tanto en la nación como en la provincia. Más allá de la convicción sobre la necesidad de reformas legislativas que definieran políticas de Estado orientadas a mejorar las condiciones de vida y de trabajo de la clase obrera, durante el desarrollo de estos conflictos, el discurso de la prensa católica se fue endureciendo

33. La Verdad, 13 de diciembre de 1930, 15 de agosto de 1931, 15 de noviembre de 1932 y 4 de mayo de 1933.

34. La Verdad, 26 de julio de 1928, 15 de agosto de 1931, 15 de marzo y 13 de junio de 1933. 
frente a las prácticas sindicales, a la vez que culpaba al nuevo gobierno de alentar la contestación social. Por la misma época, estos católicos intentaron un cambio en su estrategia politica al formar un partido propio, habida cuenta de que la reforma electoral para municipios creaba una coyuntura favorable. Si bien no tuvieron éxito, se mantuvieron líneas de acción expresadas en diversas iniciativas con el fin de ganar presencia pública focalizando en los problemas sociales, mientras la participación política transcurrió por otros carriles.

A partir de la crisis económica de 1929 los cuadros del COR se abocaron a promover distintas formas de intervención, a través de la gestión de mejoras y la presión para evitar ajustes, propiciando una campaña permanente en pro de extender la legislación del trabajo, tanto para prevenir conflictos y resolverlos, como para lograr la ampliación de beneficios del trabajador y su familia. Recurrieron asimismo a la concientización de los católicos con el objeto de que se asumieran como ciudadanos comprometidos con el proyecto de la Iglesia, refrendado en su compromiso electoral y en la defensa de la justicia social.

Se profundizaron de este modo las campañas y las acciones que, tanto desde el campo societal, como desde sus accesos e interpelaciones a diferentes organismos de gobierno, permitieran avanzar en la construcción de un Estado providencia que diera solución permanente a problemas que, en su análisis, justificaban el crecimiento de tendencias de izquierda en el ámbito político y sindical.

\section{Bibliografía}

Adamovsky, Ezequiel (2014), "Historia y lucha de clase: repensando el antagonismo social en la interpretación del pasado", en Contrahegemoníaweb: http:// contrahegemoniaweb.com.ar/historia-y-lucha-de-clase-repensando-el-antagonismo-social-en-la-interpretacion-del-pasado-y-de-vuelta-

Camarero, Hernán (2007), "El Partido comunista y los sindicatos en la Argentina durante las décadas de 1920 y 1930", en XI Jornadas Interescuelas/Departamentos de Historia, Tucumán: en Historiapolitica.com.

Caterina, Luis Maria (2008), Los empresarios y el obrerismo en tiempos radicales, 1916-1930, Rosario: PUCA-Facultad de Derecho y Ciencias Sociales de Rosario-Instituto de Historia.

Díaz Arana, J.J. (1928), Democracia y justicia social. Disertación pronunciada en la ciudad de Rosario el 5 de octubre de 1920 con los auspicios del Partido Demócrata Progresista, Rosario.

Falcón, Ricardo M. (2005), La Barcelona Argentina, Rosario: Laborde.

- y Myriam Stanley (2001), Historia de Rosario, Rosario: Homo Sapiens.

Franceschi, Gustavo J. (1936), "Pan y democracia" [1933], en Reacciones, Buenos Aires: Ediciones Católicas Argentinas.

Karush, Mathew (2006), "Radicalismo y conflicto obrero urbano, 1912-1920", 
en Nueva historia de Santa Fe. El siglo XX. Problemas sociales, politicas de Estado y economías regionales (1912-1976), Rosario: Prohistoria-La Capital.

Lida, Miranda (2015), Historia del catolicismo en la Argentina, Buenos Aires: Siglo XXI.

Lobato, Mirta, y Juan Suriano (2014), La sociedad del trabajo. Las instituciones laborales en la Argentina, 1900-1955, Buenos Aires: Edhasa.

Martín, María Pía (1993), "Sindicalismo católico y Estado corporativo", en Cuadernos del Ciesal, año $1, \mathrm{n}^{\circ}$ 1, Rosario: UNR.

- (1997), "Católicos, control ideológico y cuestión obrera. El periódico La Verdad de Rosario, 1930-1946", en Estudios Sociales. Revista Universitaria Semestral, Santa Fe: CEDEHIS-CIESAL-GEHISO-UNL.

- (2010), "El mundo católico rosarino a comienzos del siglo XX. Orden, progreso y cristiandad en el espacio local", en AA.VV., Los desafios de la modernización. Rosario, 1890-1930, Rosario: UNR.

- (2012), Iglesia católica, cuestión social y ciudadanía, Rosario-Buenos Aires, 1892-1930, tesis de doctorado, UNR.

- (2014), "Iglesia y política en los años 20", en AA.VV., Las batallas por la identidad, Rosario: Editorial Municipal de Rosario.

Mauro, Diego (2010), De los templos a las calles. Catolicismo, sociedad y politica. Santa Fe, 1900-1937, Santa Fe: Espacio Santafesino Ediciones-UNL.

- (2015), "El mutualismo católico en Argentina, el Círculo de Obreros de Rosario en la primera mitad del siglo XX", en Historia Critica, ${ }^{\circ}$ 55, Bogotá. En http://www.scielo.org.co/pdf/rhc/n55/n55a09.pdf.

Menotti, Paulo y Oscar Videla (2013), "Las huelgas de los estibadores portuarios en el sur santafesino en 1928", en Sociohistórica, $\mathrm{n}^{\circ} 32$ : http:// www.sociohistorica.fahce.unlp.edu.ar/article/view/SH2013n32a04.

Pío XI (1931), Encíclica Quadragesimo Anno: http://w2.vatican.va/content/ pius-xi/es/encyclicals/documents/hf_p-xi_enc_19310515_quadragesimo-anno.htm.

Rapalo, María Ester (2012), Patrones y obreros. La ofensiva de la clase propietaria, 1918-1930, Buenos Aires: Siglo XXI.

Roldán, Diego (2010), "Formación y reforma del municipio", en Darío G. Barriera (dir.), Instituciones, gobierno y territorio, 1725-1930, Rosario: ISHIR-Conicet.

Videla, Oscar, y Eduardo Zanella (comps.) (2004), Cuestión social, radicalismo y revisionismo en Ricardo Caballero. Historia y politica, Buenos Aires: Imago Mundi.

Zanzottera, María Guillermina (2015), "Los desplazamientos de la reforma social. Museo Social Argentino, 1911-1926", en Anuario del Centro de Estudios Históricos "Prof. Carlos S.A. Segreti", año 15, n 15, http://www. cehsegreti.org.ar/archivos/FILE_00000475_1520533624.pdf. 